\title{
Injectable shear-thinning hydrogels used to deliver endothelial progenitor cells, enhance cell engraftment, and improve ischemic myocardium
}

Ann C. Gaffey, MD, ${ }^{a}$ Minna H. Chen, BChE, ${ }^{b}$ Chantel M. Venkataraman, BA, ${ }^{a}$ Alen Trubelja, BS, Christopher B. Rodell, MS, ${ }^{\mathrm{b}}$ Patrick V. Dinh, ${ }^{\mathrm{a}}$ George Hung, BA, ${ }^{\mathrm{a}}$ John W. MacArthur, MD, ${ }^{\mathrm{a}}$ Renganaden V. Soopan, MD, ${ }^{a}$ Jason A. Burdick, PhD, ${ }^{b}$ and Pavan Atluri, MD

\begin{abstract}
Objectives: The clinical translation of cell-based therapies for ischemic heart disease has been limited because of low cell retention $(<1 \%)$ within, and poor targeting to, ischemic myocardium. To address these issues, we developed an injectable hyaluronic acid (HA) shear-thinning hydrogel (STG) and endothelial progenitor cell (EPC) construct (STG-EPC). The STG assembles as a result of interactions of adamantine- and $\beta$-cyclodextrin-modified HA. It is shear-thinning to permit delivery via a syringe, and self-heals upon injection within the ischemic myocardium. This directed therapy to the ischemic myocardial border zone enables direct cell delivery to address adverse remodeling after myocardial infarction. We hypothesize that this system will enhance vasculogenesis to improve myocardial stabilization in the context of a clinically translatable therapy.
\end{abstract}

Methods: Endothelial progenitor cells $\left(\mathrm{DiLDL}^{+} \mathrm{VEGFR}^{+} \mathrm{CD}^{+} 4^{+}\right.$) were harvested from adult male rats, cultured, and suspended in the STG. In vitro viability was quantified using a live-dead stain of EPCs. The STG-EPC constructs were injected at the border zone of ischemic rat myocardium after acute myocardial infarction (left anterior descending coronary artery ligation). The migration of the enhanced green fluorescent proteins from the construct to ischemic myocardium was analyzed using fluorescent microscopy. Vasculogenesis, myocardial remodeling, and hemodynamic function were analyzed in 4 groups: control (phosphate buffered saline injection); intramyocardial injection of EPCs alone; injection of the STG alone; and treatment with the STG-EPC construct. Hemodynamics and ventricular geometry were quantified using echocardiography and Doppler flow analysis.

Results: Endothelial progenitor cells demonstrated viability within the STG. A marked increase in EPC engraftment was observed 1-week postinjection within the treated myocardium with gel delivery, compared with EPC injection alone $(17.2 \pm 0.8$ cells per high power field (HPF) vs 3.5 cells \pm 1.3 cells per HPF, $P=.0002)$. A statistically significant increase in vasculogenesis was noted with the STG-EPC construct $(15.3 \pm 5.8$ vessels per HPF), compared with the control $(P<.0001)$, EPC $(P<.0001)$, and STG $(P<.0001)$ groups. Statistically significant improvements in ventricular function, scar fraction, and geometry were noted after STG-EPC treatment compared with the control.

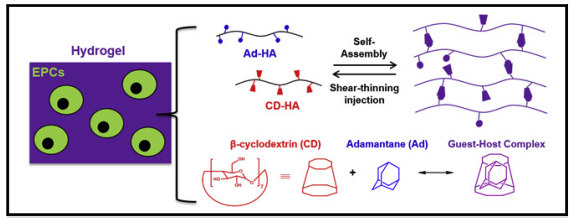

Overview of hydrogel composition; representation of STG-containing EPCs.

\section{Central Message}

A shear-thinning injectable hydrogel provides improved delivery and retention of EPCs for ischemic myocardium.

\section{Perspective}

A shear-thinning injectable hydrogel provides improved delivery and enhanced retention of EPCs for ischemic myocardium. We have investigated the mechanisms of angiogenesis associated with this therapy and the reduction in scar formation. Our data demonstrate a very significant angiogenic response and associated retention of myocardial biomechanical functioning with this therapy.

See Editorial Commentary page 1278.

See Editorial page 1035 .
From the a Division of Cardiovascular Surgery, Department of Surgery; and ${ }^{\mathrm{b}}$ Department of Bioengineering, University of Pennsylvania, Philadelphia, Pa.

Funding for this work was provided by the Thoracic Surgery Foundation for Research and Education Nina Starr Braunwald Research Fellowship (to ACG); the National Institutes of Health (R01 HL107938, R01 HL111090) (to JAB); the American Heart Association predoctoral fellowship (to CBR); and the American Association for Thoracic Surgery David C. Sabiston Research Scholarship and the American Heart Association Scientist Development Grant 13SDG17230005 (both to PA).
Read at the 95th Annual Meeting of The American Association for Thoracic Surgery, Seattle, Washington, April 25-29, 2015.

Received for publication May 3, 2015; revisions received June 30, 2015; accepted for publication July 12, 2015; available ahead of print Aug 17, 2015

Address for reprints: Pavan Atluri, MD, Division of Cardiovascular Surgery, Department of Surgery, University of Pennsylvania, Silverstein 6, 3400 Spruce St, Philadelphia PA 19104 (E-mail: Pavan.atluri@uphs.upenn.edu).

$0022-5223 / \$ 36.00$

Copyright $\odot 2015$ by The American Association for Thoracic Surgery http://dx.doi.org/10.1016/j.jtcvs.2015.07.035 

Abbreviations and Acronyms

$\begin{array}{ll}\text { Ad-HA } & =\text { adamantane-modified HA } \\ \text { CD } & =\beta \text {-cyclodextrin } \\ \text { CD-HA } & =\beta \text {-cyclodextrin-modified HA } \\ \text { DAPI } & =4^{\prime}, 6 \text {-diamidino-2-phenylindole } \\ \text { EPC } & =\text { endothelial progenitor cell } \\ \text { HA } & =\text { hyaluronic acid } \\ \text { HPF } & =\text { high power field } \\ \text { LAD } & =\text { left anterior descending } \\ \text { STG } & =\text { shear-thinning gel } \\ \text { STG-EPC } & =\text { STG-EPC construct } \\ \text { TBA } & =\text { tetrabutylammonium hydroxide }\end{array}$

Conclusions: A novel injectable shear-thinning HA hydrogel seeded with EPCs enhanced cell retention and vasculogenesis after delivery to ischemic myocardium. This therapy limited adverse myocardial remodeling while preserving contractility. (J Thorac Cardiovasc Surg 2015;150:1268-77)

Ischemic heart failure is a major global health concern. Within the United States, a myocardial infarction occurs every 34 seconds. ${ }^{1}$ Current therapies for heart failure, including both medical and surgical treatments, are palliative only and result in slight improvements in length and quality of life. Overall, a reduction in mortality from acute myocardial infarctions has occurred, but treatment strategies for those patients who develop ventricular dysfunction are still lacking. As a result, the number of patients who progress to heart failure has not improved, and both the incidence and prevalence of heart failure have increased. ${ }^{2-5}$

Cell-based therapies for treating ischemic myocardium are emerging as a treatment option for this ever-growing public health challenge. To date, numerous cell types have been used in experimental models, including fetal myocytes, embryonic stem cell-derived myocytes, skeletal myoblasts, endothelial progenitor cells (EPCs), and mesenchymal stem cells. ${ }^{6-9}$ Our lab and others have demonstrated that EPCs are easily expanded in vitro and have the ability to engraft and improve cardiac function and attenuate ventricular remodeling when delivered after infarction. ${ }^{10-14}$

Therapy with EPCs involves postnatal vasculogenesis that can be used to revascularize ischemic myocardium; they are pluripotent, bone marrow-derived stem cells with the ability to differentiate into de novo vasculature. ${ }^{15}$ Initial work was focused on cytokine therapies to locally recruit EPCs to the ischemic myocardium, because EPCs are known to promote vasculogenesis. $^{12}$ Unfortunately, translatable outcomes were marginal at best. Further studies were focused on directly delivering syngeneic EPCs locally to the damaged and hibernating myocardium. ${ }^{6,16,17}$ Both small and large animal studies showed significant vasculogenic responses in ischemic myocardium. However, the benefit has not been translatable to a sustainable clinical model.

One of the major challenges for the therapeutic application of EPCs has been optimizing cell delivery, dispersal, and engraftment. After direct cell injection into the myocardium, $<1 \%$ of the cells are retained, as shown by cell-tracking studies. ${ }^{18-21}$ Numerous factors contribute to the poor cell retention, including exposure of the cells to ischemia and inflammation, mechanical washout of cells from the beating myocardium and coronary vasculature, and leaking of the cell suspension from the targeted injection site. ${ }^{22-24}$ Overall, most cell death occurs within the first few days of cell delivery. Consequently, a delivery and stabilization mechanism is likely to promote longer cell retention and engraftment. ${ }^{24}$

One possible approach involves the use of biomaterials to provide a surrogate extracellular matrix to localize cells at the delivery site. Hydrogels in particular may provide an environment for protection from the insults of inflammation and ischemia to reduce immediate cell death upon exposure. ${ }^{12,25}$ Hydrogels are biocompatible materials that have gained increasing interest, owing to their ability to enhance cell and biomolecule delivery. ${ }^{26-30}$

We developed a shear-thinning injectable hydrogel to deliver cells to ischemic myocardium. The hydrogel was designed to flow through a syringe with application of shear force and then reassemble at the injection site. ${ }^{30}$ Tuning the properties of the hydrogel to the targeted delivery site reduces mechanical damage $\mathrm{e}^{31,32}$ and increases ability to control for cell release through gel degradation. ${ }^{31}$

Our shear-thinning gel (STG) is based on hyaluronic acid (HA) and assembles by the guest-host interactions of adamantane-modified HA (guest-macromer; Ad-HA) and $\beta$-cyclodextrin-modified HA (host-macromer; CD-HA). ${ }^{30}$ As a biomaterial, $\mathrm{HA}$ is particularly attractive, because it is found abundantly in tissue and used in biomedical applications. ${ }^{31}$ Furthermore, derivatives of adamantane are used in pharmaceuticals, and cyclodextrans are recognized by the US Food and Drug Administration as safe and approved for use in pharmaceuticals, cosmetic products, and food products. ${ }^{30}$ We have chosen to use EPCs for this study because they are readily available, highly vasculogenic, and have demonstrated clinical potential. We hypothesize that the construct of the STG with incorporation of EPCs will allow for higher cellular retention rates within the ischemic myocardium, with subsequent robust vasculogenesis and minimization of adverse ventricular remodeling.

\section{METHODS}

\section{Animal Care and Biosafety}

Male adult Wistar rats (250-300 g) were obtained from Charles River Laboratories, Inc (Boston, Mass). Food and water were provided ad libitum. This investigation adheres to the National Institutes of Health guidelines on animal care and use, conforms to institutional ethical review, and has been approved 
by the University of Pennsylvania Institutional Animal Care and Use Committee (Protocol 803394). All measurements were performed by 2 independent investigators; the design incorporated blinding to animal treatment condition.

\section{Endothelial Progenitor Cells}

Bone marrow mononuclear cells were isolated from the long bones of syngeneic adult, male Wistar rats by density-gradient centrifugation (Histopaque-1083; Sigma-Aldrich, St Louis, Mo). After isolation, the cells were seeded on vitronectin-coated plates. The cells were cultured in endothelial basal medium supplemented with human epidermal growth factor, fetal bovine serum, vascular endothelial growth factor, human fibroblast growth factor-B, R3-insulin-like growth factor, ascorbic acid, gentamicin, and amphotericin-B for 6 days (Lonza; Lonza Group AG, Basel, Switzerland). A subset of EPCs was transduced with enhanced green fluorescent protein from a Baculovirus vector (enhanced green fluorescent protein + CellLight Reagents BacMam 2.0, Life Technologies, Carlsbad, Calif). The BacMam 2.0 reagent was added directly to the cells, with approximately $90 \%$ transduction efficiency at 24 hours after transduction. The EPC phenotype $\left(\right.$ DiLDL $^{+}$VEGFR $^{+} \mathrm{CD}^{+} 4^{+}$) was previously confirmed by our group. ${ }^{10,13}$

To form the shear-thinning HA gel, sodium HA $(90 \mathrm{kDa})$ was purchased from Lifecore Biomedical LLC (Chaska, Minn). All other chemicals were purchased from Sigma-Aldrich. The sodium salt of HA was dissolved in deionized water at $2 \mathrm{wt} \%$, exchanged against Dowex-100 resin (SigmaAldrich), neutralized by tetrabutylammonium hydroxide (TBA), frozen, and lyophilized to form HA-TBA. Adamantane-modified HA (Ad-HA) was prepared by coupling 1-adamantane acetic acid to HA-TBA via esterification, as previously described. ${ }^{30}$ The $\mathrm{CD}$ was first reacted to add a hexane diamine linker to form $\beta$-CD-hexane diamine, which was coupled via amidation to HA-TBA, to form $\beta$-cyclodextrin-modified HA (CD-HA) (Figure 1).

Percent modification of the HA backbone by adamantane $(26 \%)$ or $\beta$ $\mathrm{CD}(21 \%)$ was confirmed by nuclear magnetic resonance. Hydrogels of $4 \mathrm{wt} \%$ total polymer concentration were subsequently prepared from stock solutions of Ad-HA and CD-HA in phosphate buffered saline. This STG dose was tested in a pilot study of the native heart to ensure optimal gel dose and tensile properties. To ensure a guest-host assembly mechanism, the 2 component solutions were combined and mixed manually by stirring, to ensure a homogeneous structure, which was briefly vortexed to remove entrapped air. For incorporation of the EPCs, the cells were trypsinized and counted before being mixed into the gel, to ensure a cell density of 700,000 cells per $100 \mu \mathrm{L}$ of STG. This cellular density has demonstrated improvements in vasculogenesis, as shown by our group previously. ${ }^{12}$

Male rats $(\sim 300 \mathrm{~g})$ were anesthetized with $3 \%$ isoflurane in an induction chamber (Vetequip, Inc, Pleasanton, Calif), endotracheally intubated, and mechanically ventilated (Harvard Apparatus Regenerative Technology, Holliston, Mass) with $1 \%$ isoflurane. A left lateral thoracotomy in the fourth intercostal space was performed. The proximal left anterior descending (LAD) coronary artery was identified approximately $2 \mathrm{~mm}$ below the left atrial appendage, and a 7-0 polypropylene (Prolene; Ethicon, Inc, Somerville, NJ) suture was placed around the artery and the surrounding myocardium. Regional left ventricular ischemia was induced and confirmed by discoloration of the myocardium and by changes in the cardiac rhythm. The ligation induced a consistent and reproducible anterolateral infarction of $35 \%$ to $40 \%$ of the left ventricle. ${ }^{10,33-35}$ After injection, the exposed heart was monitored for 2 to 5 minutes for stability and return to sinus rhythm.

After LAD ligation, an established method by our colleagues, ${ }^{36} 50$ animals were randomized to 1 of 4 groups: control (LAD coronary artery ligation with injection of phosphate buffered saline), intramyocardial injection of EPCs alone (700,000 cells in $100 \mu \mathrm{L}$ of phosphate buffered saline), injection of STG alone (100 $\mu$ l of STG), and treatment with the STG-EPC construct. After LAD coronary artery ligation, $18 \%$ of the animals died. A total of $100 \mu \mathrm{L}$ of STG was delivered to the myocardium with a straight 27-gauge needle into 5 sites along the anterior and posterior left ventricular wall. The area of injection corresponded to the ischemic region of the myocardium supplied by the LAD coronary artery. The chest was closed, in 3 layers, with a 3-0 polypropylene suture, and the animals were allowed to recover. Four weeks after myocardial infarction, hemodynamic analysis was conducted, and the animals were killed for histologic analysis.

To establish that EPCs from the STG had the ability to migrate into the myocardium, enhanced green fluorescent protein + EPCs, as described earlier, were incorporated into the construct (Figure 2). The STG-EPC was injected into the ischemic myocardium after LAD artery ligation. After 48 hours, the hearts were explanted, flushed with phosphate buffered saline, and distended with optimal cutting temperature embedding compound (Electron Microscopy Sciences, Hatfield, Pa). Hearts were sectioned along the short axis of the myocardium using a cryostat. Quantitative analysis was performed in the peri-infarct border zone, which was defined as 1 microscopic field from the infarct, using a fluorescent microscope. Images were taken on a Leica DM IL LED fluorescent microscope and analyzed using LAS AF, version 3.2, software (Leica Microsystems Inc, Wetzlar, Germany). Nuclei were counterstained with 4',6-diamidino-2-phenylindole (DAPI) (Vector Laboratories Inc, Burlingame, Calif). Samples were imaged at $\times 20$, and DAPI and fluorescein isothiocyanate channels were used for excitation of the sample.

\section{Quantification of Myocardial Vasculogenesis}

At 4 weeks after LAD coronary artery ligation and treatment, the hearts were explanted. Sections were washed 3 times in phosphate buffered saline, fixed in $4 \%$ paraformaldehyde for 10 minutes at room temperature, and blocked in $10 \%$ fetal bovine serum (Gibco BRL, Life Technologies, Inc, Rockville, Md) for 1 hour at $37^{\circ} \mathrm{C}$. Primary antibodies were diluted at a ratio of $1: 150$ in phosphate

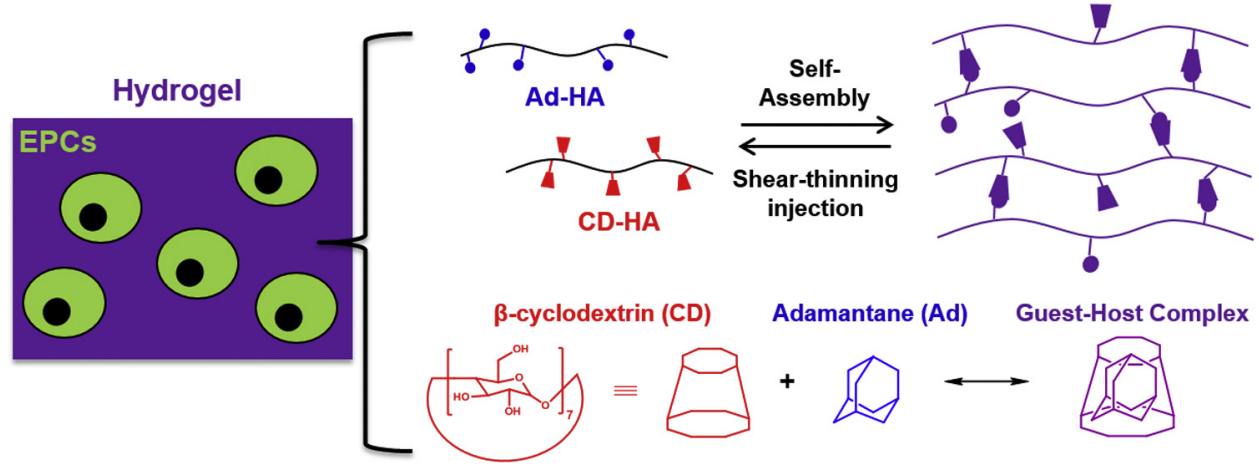

FIGURE 1. Overview of hydrogel composition. Illustration of STG-containing EPCs (left). Schematic of STG formation (right), utilizing guest-host complex of $\beta$-cyclodextrin (CD, host) and adamantane (Ad, guest) for initial self-assembly, as well as subsequent injection and self-healing in situ. EPC, Endothelial progenitor cell; $A d-H A$, adamantane hyaluronic acid; $C D-H A, \beta$-cyclodextrin hyaluronic acid. 
EPC

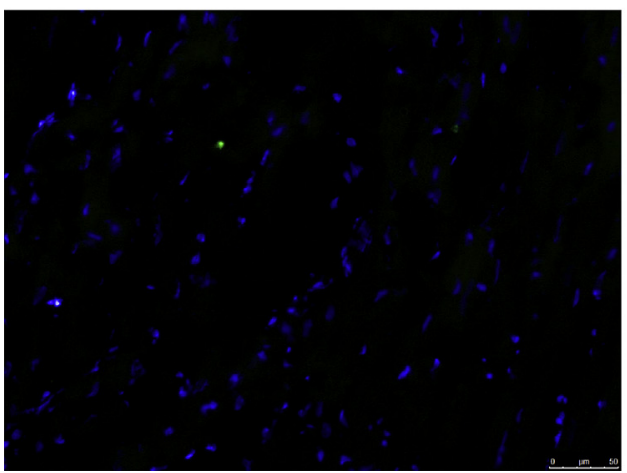

STG-EPC

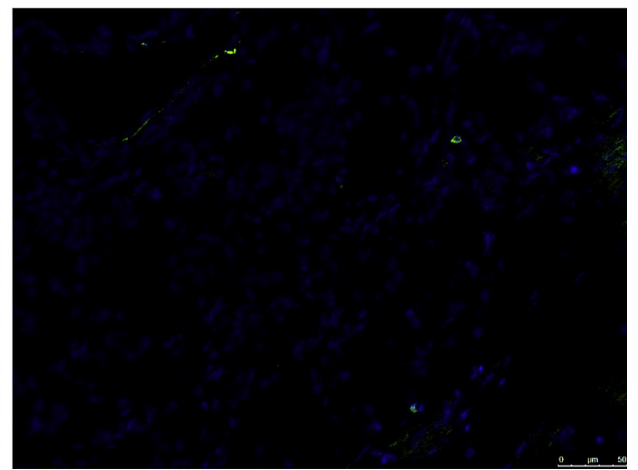

FIGURE 2. Fluorescence imaging $\times 20$ magnification of eGFP + transduced EPC migration for EPC injection alone (left) and STG-EPC (right) after 48 hours. Sections were stained for nuclei (DAPI, blue). EPC, Endothelial progenitor cell; STG, shear-thinning gel.

buffered saline and incubated for 2 hours at $37^{\circ} \mathrm{C}$. Secondary antibodies were diluted in phosphate buffered saline and incubated for 2 hours at $37^{\circ} \mathrm{C}$.

Primary antibodies included sheep anti-von Willebrand factor conjugated to fluorescein isothiocyanate and rabbit anti-smooth muscle actin (ab8822 and ab5694, respectively; Abcam, Cambridge, United Kingdom). Donkey anti-rabbit conjugated to Alexa Fluor 594 (ab150068; Abcam) was used as a secondary antibody (1:200). Nuclei were stained with DAPI. Vasculature was quantified using ImageJ (National Institutes of Health, Bethesda, Md). Measurements were made at 1 high power field (HPF) from the infarct at $\times 20$ magnification.

\section{Analysis of Myocardial Fibrosis}

At 4 weeks, hearts were explanted from animals, flushed with phosphate buffered saline, and distended with Tissue-Tek (Sakura Finetek USA, Inc, Torrance, Calif) optimal cutting temperature embedding compound. Hearts were submerged in the compound and stored at $-80^{\circ} \mathrm{C}$. Sections $(10 \mu \mathrm{m}$ thick) were prepared from each heart, using a cryostat at the level of the midpapillary muscles. Masson's trichrome stain (Accustain Trichrome Stains Kit) was performed on the sections, according to manufacturer instructions. Stained slides were scanned, and the images were analyzed, using ImageJ to assess scar fraction.

\section{Analysis of Global Ventricular Function}

Prior to explanting of the heart, transthoracic echocardiography was performed to assess myocardial function (Sonos 5500 revD system with an S12 probe [Philips Healthcare, Andover, Mass]; at $12 \mathrm{mHz}$ and a 2$\mathrm{cm}$ depth of penetration). The technician for the echocardiogram was blinded to study conditions, as were 2 independent technicians who performed review and analysis of ventricular function and volumes. Ventricular measurements were performed according to the American Society of Echocardiography leading-edge method. Additionally, a 2 French pressure-volume catheter (Millar Instruments, Inc, Houston, Tex) was inserted into the left ventricle in a retrograde fashion via the right common carotid artery for analysis of ventricular function. In addition to steadystate hemodynamic parameters, contractility was determined from pressure-volume relationships obtained by reducing preload via occlusion of the inferior vena cava. After echocardiographic and pressure-volume measurements, a sternotomy was performed, and a 2.5- $\mathrm{mm}$ ascending aortic flow probe (Transonic Systems, Inc, Ithaca, NY) was placed for Doppler analysis of cardiac output.

\section{Statistical Analysis}

Quantitative data are expressed as mean \pm SD. Statistical significance was evaluated using unpaired 2-sample $t$ tests with unequal variance. A 1-way ANOVA was performed using pairwise comparisons with Bonferroni corrections. All analyses were performed using Stata 13.1 (Stata Corporation, College Station, Tex).

\section{RESULTS}

\section{Endothelial Progenitor Cell Migration}

Immunofluorescent microscopy demonstrated a notable migration of EPCs, marked with enhanced green fluorescent protein, from the STG-EPC construct to the ischemic myocardium. A greater percentage of EPCs lie within the myocardium after treatment with STG-EPC $(11.3 \pm 4.1$ cells per HPF, $n=4)$ at 48 hours compared with EPC treatment alone, immediately after injection $(3.2 \pm 1.8$ cells per HPF; $P<.0001 ; \mathrm{n}=4)$. A marked increase of EPC incorporation within the treated myocardium was noted 1-week

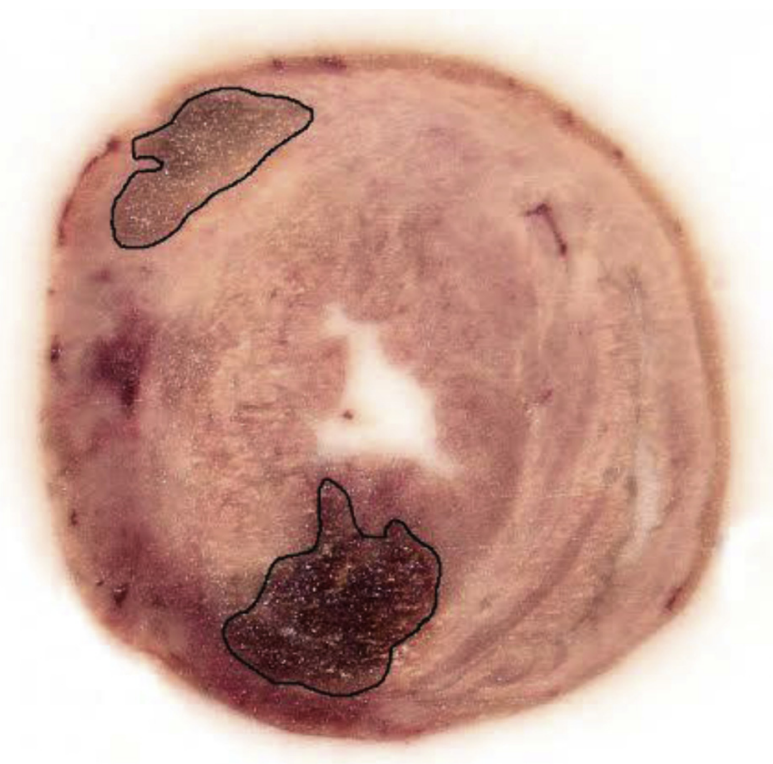

FIGURE 3. Explanted heart with delivery of the STG into the left ventricle myocardium, 48 hours after injection. 


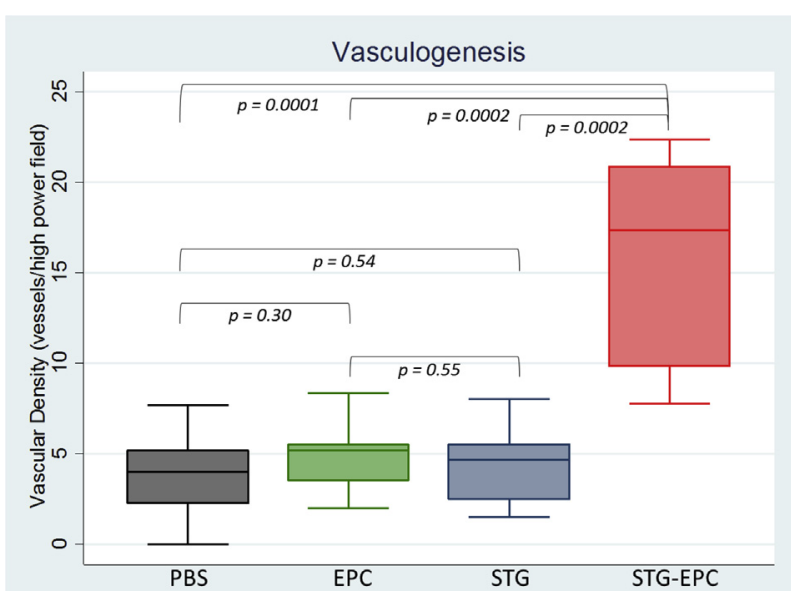

FIGURE 4. Quantification of myocardial vasculogenesis within the ischemic peri-infarct myocardium. PBS, Phosphate buffered saline; $E P C$, endothelial progenitor cell; $S T G$, shear-thinning gel.

post-implant compared with EPC alone $(17.2 \pm 0.8$ cells per HPF vs 3.5 cells \pm 1.3 cells per HPF; $P=.0002$; $\mathrm{n}=4$ ). Overall, this demonstrates a significant increase in EPC migration and retention when compared with direct cell injection. Retention of the STG within the myocardium after injection at 48 hours is clear, as shown in Figure 3.

\section{Enhancement of Myocardial Vasculogenesis}

Quantification of myocardial vasculogenesis demonstrates a statistically significant increase in vasculogenesis within the ischemic myocardium after treatment with the STG-EPC construct $(15.3 \pm 5.8$ vessels per HPF) compared with the control $(3.8 \pm 2.4$ vessels per HPF; $P<.0001$ ), as shown in Figure 4. Interestingly, the significant improvement in vasculogenesis was not evident following isolated cell injection $(5.0 \pm 2.1$ vessels per HPF), compared with control $(3.8 \pm 2.4$ vessels per HPF; $P=.30$ ). This result suggests that enhanced cell retention may contribute to significantly enhanced vasculogenesis within the ischemic myocardium (Figure 5).

\section{Minimization of Myocardial Fibrosis}

A reduction of myocardial fibrosis and ventricular scar was demonstrated in the treatment group of STG-EPC (Table 1, Figure 6). There was a significant reduction in scar fraction for the STG-EPC group $(9.9 \% \pm$ $5.6 \%)$, compared with the EPC treatment $(27.0 \% \pm$ $7.6 \% ; P<.0001$ ), correlating with limited adverse ventricular remodeling. Similarly, a statistically significant reduction in scar fraction was noted between EPC group and the control $(P=.04)$. There was no significant difference between the STG or EPC groups $(P=.07)$. Comparison of the STG group to the control demonstrated no significant difference in reduction of scar fraction $(P=.38)$.

\section{Improvement of Myocardial Function}

Hemodynamic analysis demonstrated a statistically significant improvement in left ventricular ejection fraction, cardiac output, maximum pressure, $\mathrm{dP} / \mathrm{dt}$ max, and contractility generated pressure for the STG-EPC treatment, compared with the control, shown in Tables 2 and 3. The improvement in ejection fraction was statistically different in all treatment groups (EPC, STG, and STGEPC), compared with the control; however, the greatest
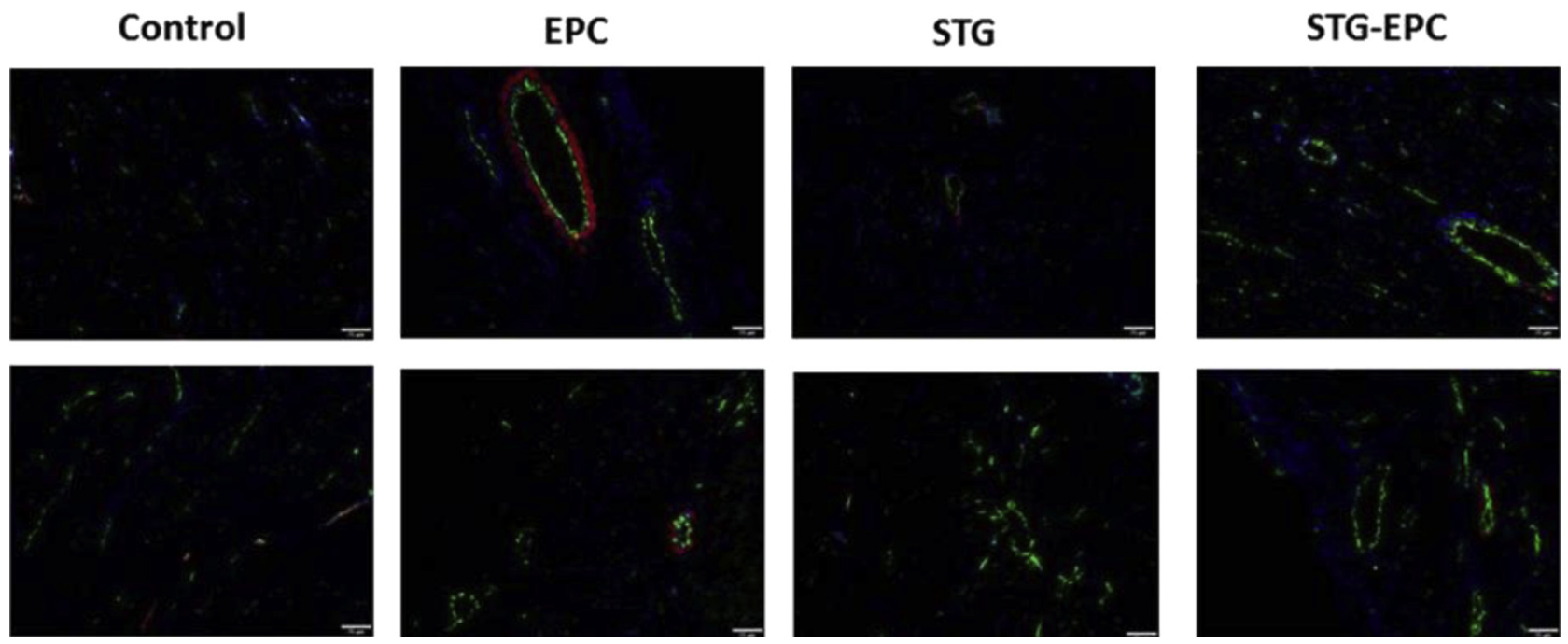

FIGURE 5. Representative immunofluorescence images of vascular structures in the peri-infarct ischemic myocardium after therapy ( $\times 20$ magnification). The von Willebrand factor is stained green; $4^{\prime}, 6$-diamidino-2-phenylindole is stained blue; and $\alpha$-smooth muscle actin is stained red. EPC, Endothelial progenitor cell; $S T G$, shear-thinning gel. 
TABLE 1. Left ventricular myocardial scar fraction 4 weeks after left anterior descending coronary artery ligation and treatment by echocardiography

\begin{tabular}{lcccc}
\hline \multicolumn{1}{c}{ Group } & $\begin{array}{c}\text { Scar fraction } \\
(\% ; \mathbf{M} \pm \mathbf{S D})\end{array}$ & $\begin{array}{c}\boldsymbol{P} \text { vs } \\
\text { control }\end{array}$ & $\begin{array}{c}\boldsymbol{P} \text { vs } \\
\text { EPC }\end{array}$ & $\begin{array}{c}\boldsymbol{P} \text { vs } \\
\text { STG }\end{array}$ \\
\hline Control $(\mathrm{n}=8)$ & $35.6 \pm 8.2$ & & .04 & .38 \\
EPC $(\mathrm{n}=10)$ & $27.0 \pm 7.6$ & .04 & & .07 \\
STG $(\mathrm{n}=13)$ & $32.6 \pm 5.3$ & .38 & .07 & \\
EPC-STG $(\mathrm{n}=10)$ & $9.9 \pm 5.6$ & $<.0001$ & $<.0001$ & $<.0001$ \\
\hline
\end{tabular}

$M$, Mean; $S D$, standard deviation; $E P C$, Endothelial progenitor cell; $S T G$, shearthinning gel.

improvement was noted in the combined treatment (STGEPC) cohort. There was no significant difference in ventricular function between the EPC $(57.3 \% \pm 10.7 \%)$ and STG $(55.6 \% \pm 12.2 \% ; P=.74)$ cohorts.

\section{DISCUSSION}

Poor cellular retention is implicated in the failure of cell-based therapies for myocardial infarction models. The lack of sustained delivery limits the achievement of clinically significant and translatable treatment methods. ${ }^{37,38}$ Much research over the past decade has focused on bioengineered, chemically modified materials to improve delivery of treatment modalities (biochemical and cellular) to ultimately preserve left ventricular function. ${ }^{6,39-41}$

In the present study, the EPC-loaded STG addresses the issue of mechanical dispersion to overcome the limitations of reduced treatment efficacy. We have shown a significant increase in EPC retention within the treatment group of STGEPC, compared with direct EPC injection. Our results are consistent with previous findings that biomaterial delivery vehicles can enhance cellular retention. ${ }^{25,42-46}$ Specifically, Liu and colleagues ${ }^{45}$ reported a 1.5 -fold increase in acute cell retention of adipose-derived mesenchymal stem cells encapsulated in chitosan/ $\beta$ - glycerophosphate-hydroxyethyl cellulose, 24 hours postadministration, compared with cells delivered in saline. ${ }^{45}$ The improved cellular retention may
TABLE 2. Left ventricular function (ejection fraction) 4 weeks after left anterior descending coronary artery ligation and treatment by echocardiography

\begin{tabular}{lcccc}
\hline \multicolumn{1}{c}{ Group } & $\begin{array}{c}\text { Left ventricle } \\
\text { ejection fraction }(\%)\end{array}$ & $\begin{array}{c}\boldsymbol{P} \text { vs } \\
\text { control }\end{array}$ & $\begin{array}{c}\boldsymbol{P} \text { vs } \\
\text { EPC }\end{array}$ & $\begin{array}{c}\boldsymbol{P} \text { vs } \\
\text { STG }\end{array}$ \\
\hline Control $(\mathrm{n}=8)$ & $42.1 \pm 5.6$ & & .005 & .001 \\
EPC $(\mathrm{n}=10)$ & $57.3 \pm 10.7$ & .005 & & .74 \\
STG $(\mathrm{n}=13)$ & $55.6 \pm 12.2$ & .001 & .74 & \\
STG-EPC $(\mathrm{n}=10)$ & $68.9 \pm 12.0$ & $<.00001$ & .03 & .006 \\
\hline
\end{tabular}

$E P C$, Endothelial progenitor cell; $S T G$, shear-thinning gel.

be a result of the STG's ability to reduce cell washout at the target site and contribute to a higher cell viability in the hypoxic/ischemic environment of the infarcted rat model heart. Clearly, the STG permits targeted therapy of a high concentration of cells, to ensure adequate engraftment.

The improved retention of cells led us to assess the implications of increased retention through ventricular remodeling and function as noted in prior studies. ${ }^{25,45,47-50}$ Our in vivo studies demonstrated that treatment with STGEPC led to smaller infarct, stimulated vasculogenesis at the border zone, and preserved left ventricle geometry and function compared with the control. In addition, the treatment with the STG alone stimulated improved vasculogenesis, albeit to a lesser degree than did the STG-EPC. Additionally, the STG treatment may have maintained left ventricular geometry by limiting infarct size through potential structural support to the myocardium during the inflammatory postinfarct state. ${ }^{40,41}$ This finding is corroborated by previous studies and is potentially a result of the interaction between HA and the membrane protein CD44 on EPCs. ${ }^{51-53}$

The use of EPCs for the treatment method, as performed in this study, highlights the ability of targeted cell delivery to improve vasculogenesis. Undoubtedly, the angiogenic strategy to therapy is valuable and potentially translatable. However, which transplantable cell type is most effective for regeneration of cardiac tissue is not clear. As shown
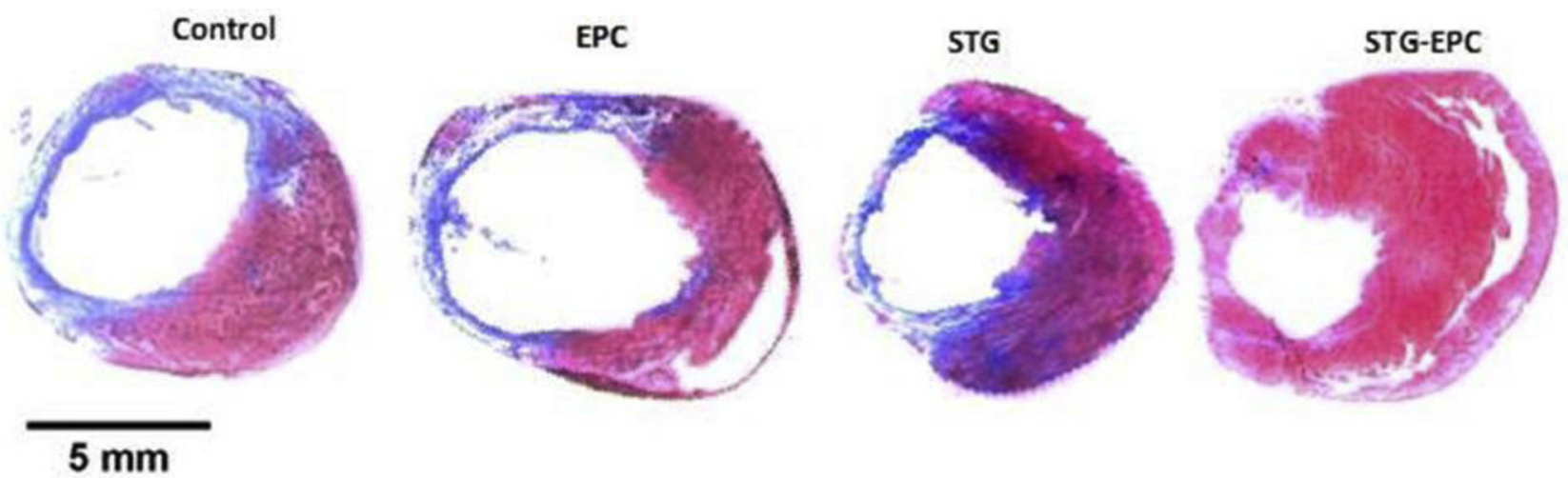

FIGURE 6. Representative myocardial cross-sectional images after trichrome staining to delineate scar (blue) on the myocardium (red). EPC, Endothelial progenitor cell; $S T G$, shear-thinning gel. 
TABLE 3. Left ventricular function 4 weeks after left anterior descending coronary artery ligation and treatment by echocardiography

\begin{tabular}{lccll}
\hline \multicolumn{1}{c}{ Group } & Control $(\mathbf{n}=\mathbf{8})$ & EPC $(\mathbf{n}=\mathbf{1 0})$ & \multicolumn{1}{c}{ STG $(\mathbf{n}=\mathbf{1 3})$} & \multicolumn{1}{c}{ STG-EPC $(\mathbf{n}=\mathbf{1 0})$} \\
\hline $\mathrm{CO}(\mathrm{mL} / \mathrm{min})$ & $16.3 \pm 4.1$ & $28.3 \pm 5.2$ & $24.8 \pm 2.1(P=.005)$ & $46.8 \pm 7.0(P<.00001)$ \\
Maximum pressure $(\mathrm{mm} \mathrm{Hg})$ & $50.8 \pm 6.7$ & $74.3 \pm 5.6$ & $96.2 \pm 7.7(P<.00001)$ & $98.7 \pm 17.0(P<.00001)$ \\
dP/dt max $(\mathrm{mm} \mathrm{Hg} / \mathrm{s})$ & $2037 \pm 89.2$ & $2496 \pm 65.6$ & $2547.3 \pm 248.1(P=.52)$ & $5812.1 \pm 237.3(P<.00001)$ \\
Contractility $(\mu \mathrm{L} / \mathrm{mm} \mathrm{Hg})$ & $1.2 \pm 0.2$ & $1.5 \pm 0.08$ & $2.2 \pm 0.1(P=.003)$ & $2.8 \pm 0.1(P=.004)$ \\
\hline
\end{tabular}

$\mathrm{CO}$ was quantified using an ascending aortic flow probe; maximum pressure and $\mathrm{dP} / \mathrm{dt}$ were measured with an intraventricular pressure-volume catheter. $P$ values are in relation to EPC treatment. EPC, Endothelial progenitor cell; $S T G$, shear-thinning gel; $C O$, cardiac output.

by Korf-Klingebiel and colleagues, ${ }^{54}$ mesenchymal stem cells have been shown to release cytokines, growth factors, and chemokines to help in cardiac repair. Future work may focus on the incorporation of myogenic therapy, as well as a combination of angiogenic and myogenic therapy to evaluate improvements in cardiac function. ${ }^{6,55}$

Overall, biomaterials are tunable in terms of mechanical properties, rates of degradation, and chemical composition. Specifically, the injectable HA-based STG used in this study is dependent on the reversible dynamic bonds of the guest-host interaction between adamantane and $\beta$-cyclodextrin. As previously described, the shear-thinning behavior can be tuned through adjustment of the macromer concentrations and modifications, to influence material properties, and is able to be injected and retained at the targeted site. ${ }^{30,56}$ Through such alterations, gel degradation can additionally be designed for a specific application and tissue target.

Moreover, compared with our prior work with a fibrin gel patch, ${ }^{12}$ as well as work by Roche and colleagues, ${ }^{25}$ the injectable hydrogel shows promise in its ability to target multiple small infarct areas. Additionally, HA is known to stimulate angiogenesis in vivo with necrotic tissue. ${ }^{57}$ The pro-angiogenic properties of blank HA certainly make it a stimulus that will enable tissue engineering of neovascularized and functional tissue. These properties serve to explain the preservation of ventricular function in the empty STG control, as well as the ability to mechanically stabilize the myocardium and prevent infarction expansion.

The current method, exemplified in this study, utilizes direct intramyocardial delivery; thus, it is invasive, requiring a thoracotomy for multi-injections. Nevertheless, as delivery of the STG aims to advance to endocardial application using catheters, the overall invasive nature will decrease to a possible percutaneous approach. Clearly, this method of targeted cell delivery demonstrates a therapeutic applicability to the wider spectrum of infarctionmediated myocardial damage and should be considered for future cell therapy. Given that the STG parameters of hydrogel erosion and cell and/or biomolecule release can be designed and controlled means they are likely to continue to be used in future applications.

In addition to the direct cellular effects of the EPCs on the myocardium, a paracrine influence from the delivery of cells may occur, suggesting that transplanted cells release soluble factors that help regenerate the heart. ${ }^{54,58,59}$ This hypothesis is supported by Gnecchi and colleagues, ${ }^{58}$ who demonstrated the ability to recreate the effects of cell therapy with conditioned media. Proposed mechanisms for the paracrine effects include modulation of inflammatory responses, up-regulation of vasculogenesis, and protection of cardiac cell cycle re-entry. ${ }^{60}$ If we relate this to our study, the STG may be able to exert enhanced efficacy as a result of superior cell retention. Clearly, further investigation is warranted.

\section{Limitations}

One limitation of this study is that it was performed in a rodent model of acute myocardial infarction, in which treatment was given immediately after coronary ligation. Although this satisfies our hypothesis for how the STGEPC treatment interacts with ischemic myocardium, the positive findings reported may not be generally applied to clinical situations of primarily chronic heart failure. However, as a proof-of-principle study and starting point for future work in both chronic models and larger animal studies, we have effectively shown that STG-EPC delivery is possible, with improvements in cellular retention translating into increased vasculogenesis and improved perfusion.

\section{CONCLUSIONS}

The novel tissue-engineered biomaterial used in this study may improve cell-based therapies by allowing investigators to enhance delivery of the desired cell, use multiple cell types, incorporate concomitant cytokine therapy, and provide gel-mediated myocardial stabilization. This intricate cell-delivery strategy may provide the robust clinical response needed to normalize myocardial function. We believe that several avenues of research could be explored as a next step in this therapeutic strategy, including noninvasive longitudinal cell tracking, definition of paracrine mechanisms, and biomechanical improvements. Prior to clinical translation, preclinical large animal therapies are warranted. Clinically, the STG is an exciting method of targeted therapeutic delivery, possibly in both open surgical and percutaneous procedures.

We have presented an STG that acts as a delivery mechanism for EPC-mediated therapy, to enhance cell retention 
and vasculogenesis to the myocardium after infarction. Through this study, we have shown the following. The HA injectable STG can enhance cell retention at the hypoxic border zone of the ischemic myocardium. The STG permits localized and targetable therapy in the heart. This therapy leads to in vivo improvements that include enhanced vasculogenesis, limited adverse remodeling, and improved cardiac function.

\section{Conflict of Interest Statement}

Authors have nothing to disclose with regard to commercial support.

You can watch a Webcast of this AATS meeting presentation by going to: http://webcast.aats.org/2015/Video/Tuesday/ 04-28-15_6B_0710_Gaffey.mp4

\section{References}

1. Go AS, Mozaffarian D, Roger VL, Benjamin EJ, Berry JD, Blaha MJ, et al. Heart disease and stroke statistics-2013 update: a report from the American Heart Association. Circulation. 2013;127:e6-245.

2. Araszkiewicz A, Grajek S, Lesiak M, Prech M, Pyda M, Janus M, et al. Effect of impaired myocardial reperfusion on left ventricular remodeling in patients with anterior wall acute myocardial infarction treated with primary coronary intervention. Am J Cardiol. 2006;98:725-8.

3. Bolognese L, Carrabba N, Parodi G, Santoro GM, Buonamici P, Cerisano G, et al. Impact of microvascular dysfunction on left ventricular remodeling and longterm clinical outcome after primary coronary angioplasty for acute myocardial infarction. Circulation. 2004;109:1121-6.

4. Velazquez EJ, Lee KL, Deja MA, Jain A, Sopko G, Marchenko A, et al. Coronary-artery bypass surgery in patients with left ventricular dysfunction. $N$ Engl J Med. 2011;364:1607-16.

5. Davis DR, Zhang Y, Smith RR, Cheng K, Terrovitis J, Malliaras K, et al. Validation of the cardiosphere method to culture cardiac progenitor cells from myocardial tissue. PLoS One. 2009; 4:e7195.

6. Pavo N, Charwat S, Nyolczas N, Jakab A, Murlasits Z, Bergler-Klein J, et al. Cell therapy for human ischemic heart diseases: critical review and summary of the clinical experiences. J Mol Cell Cardiol. 2014;75:12-24.

7. Iglesias-García O, Pelacho B, Prósper F. Induced pluripotent stem cells as a new strategy for cardiac regeneration and disease modeling. J Mol Cell Cardiol.2013; 62:43-50.

8. Cao G, Liu C, Wan Z, Liu K, Sun H, Sun X, et al. Combined hypoxia inducible factor- $1 \alpha$ and homogeneous endothelial progenitor cell therapy attenuates shunt flow-induced pulmonary arterial hypertension in rabbits. $J$ Thorac Cardiovasc Surg. 2015;150:621-32.

9. Lambert V, Gouadon E, Capderou A, Le Bret E, Ly M, Dinanian S, et al. Right ventricular failure secondary to chronic overload in congenital heart diseases: benefits of cell therapy using human embryonic stem cell-derived cardiac progenitors. J Thorac Cardiovasc Surg. 2015;149:708-15.e1.

10. Atluri P, Trubelja A, Fairman AS, Hsiao P, MacArthur JW, Cohen JE, et al. Normalization of postinfarct biomechanics using a novel tissue-engineered angiogenic construct. Circulation. 2013;128:S95-104.

11. Atluri P, Panlilio CM, Liao GP, Hiesinger W, Harris DA, McCormick RC, et al. Acute myocardial rescue with endogenous endothelial progenitor cell therapy. Heart Lung Circ. 2010;19:644-54.

12. Atluri P, Miller JS, Emery RJ, Hung G, Trubelja A, Cohen JE, et al. Tissue-engineered, hydrogel-based endothelial progenitor cell therapy robustly revascularizes ischemic myocardium and preserves ventricular function. J Thorac Cardiovasc Surg. 2014;148:1090-7; discussion 1097-98.

13. Frederick JR, Fitzpatrick JR, McCormick RC, Harris DA, Kim AY, Muenzer JR, et al. Stromal cell-derived factor-1alpha activation of tissueengineered endothelial progenitor cell matrix enhances ventricular function after myocardial infarction by inducing neovasculogenesis. Circulation. 2010; 122:S107-17.
14. Treskes P, Neef K, Perumal Srinivasan S, Halbach M, Stamm C, Cowan D, et al Preconditioning of skeletal myoblast-based engineered tissue constructs enables functional coupling to myocardium in vivo. J Thorac Cardiovasc Surg. 2015; 149:348-56

15. Leeper NJ, Hunter AL, Cooke JP. Stem cell therapy for vascular regeneration: adult, embryonic, and induced pluripotent stem cells. Circulation. 2010;122: 517-26.

16. Zhang Y, Ingram DA, Murphy MP, Saadatzadeh MR, Mead LE, Prater DN, et al Release of proinflammatory mediators and expression of proinflammatory adhesion molecules by endothelial progenitor cells. Am J Physiol Heart Circ Physiol. 2009;296:H1675-82.

17. Tse HF, Siu CW, Zhu SG, Songyan L, Zhang QY, Lai WH, et al. Paracrine effects of direct intramyocardial implantation of bone marrow derived cells to enhance neovascularization in chronic ischaemic myocardium. Eur J Heart Fail. 2007;9: 747-53.

18. Sheikh AY, Huber BC, Narsinh KH, Spin JM, van der Bogt K, de Almeida PE, et al. In vivo functional and transcriptional profiling of bone marrow stem cells after transplantation into ischemic myocardium. Arterioscler Thromb Vasc Biol. 2012;32:92-102.

19. Hofmann M, Wollert KC, Meyer GP, Menke A, Arseniev L, Hertenstein B, et al. Monitoring of bone marrow cell homing into the infarcted human myocardium. Circulation. 2005;111:2198-202.

20. Schächinger V, Aicher A, Döbert N, Rover R, Diener J, Fichtlscherer S, et al. Pilot trial on determinants of progenitor cell recruitment to the infarcted human myocardium. Circulation. 2008;118:1425-32.

21. Li S-H, Lai TY, Sun Z, Han M, Moriyama E, Wilson B, et al. Tracking cardiac engraftment and distribution of implanted bone marrow cells: comparing intraaortic, intravenous, and intramyocardial delivery. J Thorac Cardiovasc Surg. 2009; 137:1225-33.e1.

22. Wang H, Zhou J, Liu Z, Wang C. Injectable cardiac tissue engineering for the treatment of myocardial infarction. J Cell Mol Med. 2010;14: 1044-55.

23. Laflamme MA, Chen KY, Naumova AV, Muskheli V, Fugate JA, Dupras SK et al. Cardiomyocytes derived from human embryonic stem cells in prosurvival factors enhance function of infarcted rat hearts. Nat Biotechnol. 2007;25:1015-24.

24. Robey TE, Saiget MK, Reinecke H, Murry CE. Systems approaches to preventing transplanted cell death in cardiac repair. J Mol Cell Cardiol. 2008;45: 567-81.

25. Roche ET, Hastings CL, Lewin SA, Shvartsman DE, Brudno Y, Vasilyev NV, et al. Comparison of biomaterial delivery vehicles for improving acute retention of stem cells in the infarcted heart. Biomaterials. 2014;35:6850-8

26. McCall JD, Lin CC, Anseth KS. Affinity peptides protect transforming growth factor beta during encapsulation in poly(ethylene glycol) hydrogels. Biomacromolecules. 2011;12:1051-7.

27. Lin CC, Sawicki SM, Metters AT. Free-radical-mediated protein inactivation and recovery during protein photoencapsulation. Biomacromolecules. 2008;9: $75-83$.

28. Williams CG, Malik AN, Kim TK, Manson PN, Elisseeff JH. Variable cytocom patibility of six cell lines with photoinitiators used for polymerizing hydrogels and cell encapsulation. Biomaterials. 2005;26:1211-8.

29. Bryant SJ, Nuttelman CR, Anseth KS. Cytocompatibility of UV and visible ligh photoinitiating systems on cultured NIH/3T3 fibroblasts in vitro. J Biomater Sci Polym Ed. 2000;11:439-57.

30. Rodell CB, Kaminski AL, Burdick JA. Rational design of network properties in guest-host assembled and shear-thinning hyaluronic acid hydrogels. Biomacromolecules. 2013;14:4125-34.

31. Lu HD, Charati MB, Kim IL, Burdick JA. Injectable shear-thinning hydrogels engineered with a self-assembling Dock-and-Lock mechanism. Biomaterials 2012;33:2145-53.

32. Dankers PY, van Leeuwen EN, van Gemert GM, Spiering AJ, Harmsen MC Brouwer LA, et al. Chemical and biological properties of supramolecular polymer systems based on oligocaprolactones. Biomaterials. 2006;27: 5490-501.

33. Liu YH, Yang XP, Nass O, Sabbah HN, Peterson E, Carretero OA. Chronic heart failure induced by coronary artery ligation in Lewis inbred rats. Am J Physiol. 1997;272:H722-7.

34. Atluri P, Liao GP, Panlilio CM, Hsu VM, Leskowitz MJ, Morine KJ, et al. Neovasculogenic therapy with granulocyte-monocyte colony stimulating factor and stromal cell derived factor- $1 \alpha$ augments perfusion, reverses ischemia and 
preserves cardiomyocyte viability in ischemic cardiomyopathy. Ann Thorac Surg. 2006;81:1728-36.

35. MacArthur JW, Trubelja A, Shudo Y, Hsiao P, Fairman AS, Yang E, et al. Mathematically engineered stromal cell-derived factor- $1 \alpha$ stem cell cytokine analog enhances mechanical properties of infarcted myocardium. J Thorac Cardiovasc Surg. 2013;145:278-84

36. Woo YJ, Grand TJ, Berry MF, Atluri P, Moise MA, Hsu VM, et al. Stromal cell-derived factor and granulocyte-monocyte colony-stimulating factor form a combined neovasculogenic therapy for ischemic cardiomyopathy. J Thorac Cardiovasc Surg. 2005;130:321-9.

37. Templin C, Lüscher TF, Landmesser U. Cell-based cardiovascular repair and regeneration in acute myocardial infarction and chronic ischemic cardiomyopathy-current status and future developments. Int J Dev Biol. 2011; 55:407-17.

38. Singelyn JM, Christman KL. Injectable materials for the treatment of myocardial infarction and heart failure: the promise of decellularized matrices. J Cardiovasc Transl Res. 2010;3:478-86.

39. Eckhouse SR, Purcell BP, McGarvey JR, Lobb D, Logdon CB, Doviak H, et al. Local hydrogel release of recombinant TIMP-3 attenuates adverse left ventricular remodeling after experimental myocardial infarction. Sci Transl Med. 2014;6: $223 \mathrm{ra} 21$.

40. Morita M, Eckert CE, Matsuzaki K, Noma M, Ryan LP, Burdick JA, et al. Modification of infarct material properties limits adverse ventricular remodeling. Ann Thorac Surg. 2011;92:617-25.

41. Tous E, Ifkovits JL, Koomalsingh KJ, Shuto T, Soeda T, Kondo N, et al. Influence of injectable hyaluronic acid hydrogel degradation behavior on infarction-induced ventricular remodeling. Biomacromolecules. 2011;12: 4127-35.

42. Hamdi H, Furuta A, Bellamy V, Bel A, Puymirat E, Peyrard S, et al. Cell delivery: intramyocardial injections or epicardial deposition? A head-to-head comparison. Ann Thorac Surg. 2009;87:1196-203.

43. Smith RR, Marbán E, Marbán L. Enhancing retention and efficacy of cardiosphere-derived cells administered after myocardial infarction using a hyaluronan-gelatin hydrogel. Biomatter. 2013; http://dx.doi.org/10.4161/ biom. 24490 .

44. Qian L, Shim W, Gu Y, Shirhan M, Lim KP, Tan LP, et al. Hemodynamic contribution of stem cell scaffolding in acute injured myocardium. Tissue Eng Part A. 2012;18:1652-63.

45. Liu Z, Wang H, Wang Y, Lin Q, Yao A, Cao F, et al. The influence of chitosan hydrogel on stem cell engraftment, survival and homing in the ischemic myocardial microenvironment. Biomaterials. 2012;33:3093-106.

46. Feng XD, Wang XN, Yuan XH, Wang W. Effectiveness of biatrial epicardial application of amiodarone-releasing adhesive hydrogel to prevent postoperative atrial fibrillation. J Thorac Cardiovasc Surg. 2014; 148:939-43.

47. Cheng K, Li TS, Malliaras K, Davis DR, Zhang Y, Marbán E. Magnetic targeting enhances engraftment and functional benefit of iron-labeled cardiosphere-derived cells in myocardial infarction. Circ Res. 2010;106: 1570-81.

48. Terrovitis J, Lautamäki R, Bonios M, Fox J, Engles JM, Yu J, et al. Noninvasive quantification and optimization of acute cell retention by in vivo positron emission tomography after intramyocardial cardiac-derived stem cell delivery. J Am Coll Cardiol. 2009;54:1619-26.

49. Quevedo HC, Hatzistergos KE, Oskouei BN, Feigenbaum GS, Rodriguez JE, Valdes D, et al. Allogeneic mesenchymal stem cells restore cardiac function in chronic ischemic cardiomyopathy via trilineage differentiating capacity. Proc Natl Acad Sci U S A. 2009;106:14022-7.

50. Luo J, Weaver MS, Dennis JE, Whalen E, Laflamme MA, Allen MD. Targeting survival pathways to create infarct-spanning bridges of human embryonic stem cell-derived cardiomyocytes. J Thorac Cardiovasc Surg. 2014;148: 3180-8.e1.

51. Purcell BP, Elser JA, Mu A, Margulies KB, Burdick JA. Synergistic effects of SDF-1alpha chemokine and hyaluronic acid release from degradable hydrogels on directing bone marrow derived cell homing to the myocardium. Biomaterials. 2012;33:7849-57.

52. Avigdor A, Goichberg P, Shivtiel S, Dar A, Peled A, Samira S, et al. CD44 and hyaluronic acid cooperate with SDF-1 in the trafficking of human CD34+ stem/ progenitor cells to bone marrow. Blood. 2004;103:2981-9.

53. Huebener P, Abou-Khamis T, Zymek P, Bujak M, Ying X, Chatila K, et al. CD44 is critically involved in infarct healing by regulating the inflammatory and fibrotic response. J Immunol. 2008;180:2625-33.
54. Korf-Klingebiel M, Kempf T, Sauer T, Brinkmann E, Fischer P, Meyer GP, et al. Bone marrow cells are a rich source of growth factors and cytokines: implications for cell therapy trials after myocardial infarction. Eur Heart J. 2008; 29:2851-8.

55. Jiang Q, Song P, Wang E, Li J, Hu S, Zhang H. Remote ischemic postconditioning enhances cell retention in the myocardium after intravenous administration of bone marrow mesenchymal stromal cells. J Mol Cell Cardiol. 2013;56: $1-7$.

56. Rodell CB, MacArthur JW, Dorsey SM, Wade RJ, Wang LL, Woo YJ, et al. Shear-thinning supramolecular hydrogels with secondary autonomous covalent crosslinking to modulate viscoelastic properties in vivo. Adv Funct Mater. 2014;25:636-44.

57. Pardue EL, Ibrahim S, Ramamurthi A. Role of hyaluronan in angiogenesis and its utility to angiogenic tissue engineering. Organogenesis. 2008;4: 203-14.

58. Gnecchi M, He H, Noiseux N, Liang OD, Zhang L, Morello F, et al. Evidence supporting paracrine hypothesis for Akt-modified mesenchymal stem cellmediated cardiac protection and functional improvement. FASEB J. 2006;20: $661-9$.

59. Schuetze KB, McKinsey TA, Long CS. Targeting cardiac fibroblasts to treat fibrosis of the heart: focus on HDACs. J Mol Cell Cardiol. 2014; 70:100-7.

60. Malliaras K, Marbán E. Cardiac cell therapy: where we’ve been, where we are, and where we should be headed. Br Med Bull. 2011;98:161-85.

Key Words: ischemic myocardium, cellular therapy, hydrogel, shear-thinning gel

\section{Discussion}

Dr T. Yau (Toronto, Ontario, Canada). Drs Chen and Crestanello, members, and guests: Thank you to the association for the privilege of discussing this paper, and to the authors for providing me with their manuscript well in advance. I have no disclosures.

In this carefully designed and intriguing study, Dr Gaffey and her colleagues have demonstrated that this combination of a novel shear-thinning hydrogel with EPCs can increase cell migration or retention in the myocardium, vasculogenesis and left ventricular systolic function, and that it modulates adverse ventricular remodeling at 4 weeks in a rat infarct model.

In some outcome measures, such as vasculogenesis, neither EPCs alone nor the hydrogel alone had an effect compared with control, whereas the combination had a pronounced effect. As Dr Gaffey noted, this apparent lack of effect of EPC alone on vasculogenesis is in some ways surprising. In other outcomes, such as those related to left ventricular systolic function, either therapy alone had some benefit, but the combination yielded a significant further improvement.

I have several questions, primarily related to the effects, in vivo behavior, and degradation of your novel shear-thinning hydrogel. Although scar morphometric data other than scar fraction are not presented, the representative cross-sections of the myocardium seem to show that the scar thickness is significantly less in the STG group than in the saline-injected controls. In addition, the scar fraction in the hydrogel group was not different than that in controls. One might expect, and other studies utilizing different kinds 
of physical scaffolds have indicated, that the mechanical support afforded by their hydrogel alone would result in less thinning and dilatation of the scar and perhaps partial improvement in function through diastolic stabilization. Do you have any thoughts on why this effect was not observed in your study?

Dr Ann C. Gaffey (Philadelphia, Pa). Thank you very much, Dr Yau, for your question. In regard to the STG, this is actually a very soft gel that we use, based upon the polymer weights of the beta-CD-modified HA and adamantine-modified HA, and because of that, we believe that at the 4-week timepoint, it actually is completely dissolved and has released its entire payload of the cells. Currently, our thought is, as we move into phase 2 of our study, that we will be able to study the gel and see at what timepoint it actually degrades.

Dr T. Yau. As you indicated, the shear stresses applied to this hydrogel during injection permit fluid-like behavior and subsequent reassembly in the myocardium; but obviously, ongoing shear stresses are generated by myocardial contraction, which might lead to microscopic or macroscopic areas of hydrogel liquefaction. Do you have any evidence or suggestion that this phenomenon does or does not occur after you deliver this into the myocardium; and would you expect this to differ if you are injecting this into an akinetic scar versus a normally contractile myocardium?

Dr A. Gaffey. Absolutely. So based upon following injection of the gel, I believe that through the stress of the heart, it does aid in the delivery of the cells. As I stated before, it is a soft gel; and so as a result, I think it does permit easy release of the payload. However, once we determine the optimal gel density or stiffness of the gel, potentially that will decrease its ability to shear stress at the time of the beating of the heart.

Dr Yau. The last question is just to elaborate on one of your previous replies. What is the time course of STG degradation after this injection in vivo? I think that in some of your sections, you indicate, or they show, that out to 4 weeks, the STG is still present to some degree. But given that the EPC of the gel alone had variable effects, and the individual components had no effect on vasculogenesis, do you expect the effects of this combination therapy to persist after the gel has been completely degraded; and if so, why?

Dr Gaffey. I think the initial benefit of the gel is the cell retention at the ischemic border zone at the immediate time. We have seen the gel present at about 1 week out, and currently we are studying when the degradation occurs. I do not have a specific timepoint, whether it is at 3 weeks; but we are not able to see the gel at 4 weeks out, so it is not present at that time.

Dr Yau. Thank you and congratulations on a meticulously performed and well presented study.

Dr Gaffey. Thank you very much.

Dr J. Mayer (Boston, Mass). I just have one quick question, and that is, when were the EPCs added to the gel, and how long were they in contact with the gel?

Dr A. Gaffey. We lift the EPCs off the plate, immediately vortex them, incorporate them into the gel, and inject. The entire process takes about 30 minutes.

Dr M. Slaughter (Louisville, Ky). Any time you directly inject something with a tuberculosis-like syringe, it is very operator dependent; it depends on the angle of the needle, the speed with which the plunger is moved forward, and timing with systolic contraction. As you know, you can get extrusion of the material with systole. Did you quantify how much of the hydrogel was actually retained after injection? Given that it dissolves, is there any way to tell how much actually was active, and for how long?

Dr A. Gaffey. I think that is an important question. You do point out that we do 5 injections at the border zone. Depending on the operator, you can see backflow of the gel. We leave the needle in the myocardium for about $15 \mathrm{sec}-$ onds, to minimize gel backflow; this approach results in a reproducible and consistent volume of gel delivery following LAD ligation. I do not have a quantification of the amount of gel. We inject about 100 microliters per animal, which is 20 microliters per injection site (5 sites total). 